\title{
Women in community radio: a framework of gendered participation
}

\section{Anne O'Brien}

To cite this article: Anne O'Brien (2019) Women in community radio: a framework of gendered participation, Feminist Media Studies, 19:6, 787-802, DOI: 10.1080/14680777.2018.1508051

To link to this article: https://doi.org/10.1080/14680777.2018.1508051

曲 Published online: 29 Aug 2018.

Submit your article to this journal 준

Џlll Article views: 466

Q View related articles ¿

View Crossmark data \ulcorner

Citing articles: 1 View citing articles $\square$ 


\title{
Women in community radio: a framework of gendered participation
}

\author{
Anne O'Brien
}

Department of Media Studies, Maynooth University, Maynooth, Ireland

\begin{abstract}
Women's participation in community radio is examined through a case study of Ireland, with data gathered by survey, interviews and a focus group. Key findings note that women are under-represented as participants in community radio, but there is little activity within the sector to address this imbalance. Similarly, women's voices are absent from community airwaves but this is framed through a limited understanding women lacking on-air confidence. Solutions to the problem were limited to individual stations rather than approached in a collective manner. There was no sense of women's voices on air being a priority issue for stations, for the sector, nor for the national regulatory body. With regard to content, stations largely tended to produce "islands" of specialist women's programmes but there was a sense that women produced content in ways that were not normative and were explicitly linked to gender. Gendered social structures, as well as organisational structures within community radio, constituted further barriers to women's equal participation in community radio in Ireland. Finally, the presence of women as role models, sponsors, and managers, who were relational in their approach, was key gendered benefits that women derived from their participation in community radio.
\end{abstract}

\section{ARTICLE HISTORY}

Received 11 December 2017

Revised 10 June 2018

Accepted 19 June 2018

\section{KEYWORDS}

Community radio; gender; presenters; content; participation

For over a decade, Irish campaign groups such as Women on Air, the Film Writers Guild and Women in Film and Television have highlighted women's under-representation on screen, on air and within the television and film workforce in Ireland. Similarly, accounts of women's marginalization have been presented in various academic studies, which show that Ireland's record on gender equality is poor. Ireland falls behind the European average of $44 \%$ female employment in programming and broadcasting, with a rate of $30 \%$ participation, and a rate of only $12 \%$ participation by women in senior decision making roles (EIGE 2013, 16). In the film sector, in the 20-year period 1993-2013, only $13 \%$ of Irish-produced screenplays were penned by female writers (Susan Liddy 2015). However, less attention has been paid to date to women workers in radio production in Ireland. Despite radio being a very popular medium in Ireland-according to Joint National Listenership Research (JNLR) figures, national listenership is at $83 \%$, or 3.1 million adults listening every weekday-there is a dearth of research on the position of women workers in that sector (JNLR 2017). 
Academic research has explored the history of women's participation in radio (Anya Luscombe 2013; Jim Grubbs 2004). Anne McKay charts the socially based origins of negative attitudes to women in radio, where men's voices were credited with authority while women were constructed as passive and largely domestic audience members (Caroline Mitchell 2000). Anne Karpf conducted one of the earliest studies on women's employment in radio (1987) and Maria Gibbons (in Mitchell 2000) looked at their employment in Irish independent radio in the late 1990s. Gibbons notes that women were typically underrepresented in media work and disproportionately engaged in non-standard employment such as part time or contract work (225). She observes that women suffered from a pay gap as well as horizontal and vertical segregation in the sector, with women dominant in lower hierarchical levels and in general administration and production support roles (225). While affirmative action in the 1990s improved women's employment status in the USA, Susan Carter (2004) observes that increases in numbers employed has not yet translated into meaningful positions of power for women in radio. A situation duplicated in Ireland, where only $12 \%$ of senior decision makers in media industries are women (EIGE 2013). Tanja Bosh (2016) notes the ongoing absence of women's voices as radio presenters. Sue Steward and Sherly Garratt (1984) and Rosalind Gill (1993) examine the absence of female DJs and the "flexible sexism" that is applied in layered ways to maintain women's exclusion from mainstream radio.

The relative under-examination of women's participation in radio is even more evident and unfortunate in the context of community radio, because its entire reason to exist is founded on fostering greater social inclusion and ensuring a diversity of voices on air. The World Association of Community Radio Broadcasters (AMARC) defines the objective of community radio, as striving to "combat poverty, exclusion and voicelessness and to promote social justice and sustainable, democratic and participatory human development" (AMARC 2011). AMARC works to "reinforce the social, developmental and humanitarian impact of community media." (AMARC 2011) The primary agenda of community broadcasting, which distinguishes it from public service and commercial equivalents, is that it is founded on democratic participation. Community radio constitutes a distinctive form of media with strong connections to members of the local geographic community or community of interest that it is licensed to serve. This fundamentally means that every community radio broadcaster should have

...A democratic dimension... in the management of the station and in the production of its programs. Community radio is accessible; it is neither the expression of political power nor the expression of capital. It is the expression of the population. (Jan Servaes 1999, 260)

Some of the diverse ways in which community radio has achieved its democratizing mandate are evidenced by: its role in representing and contributing to local culture (Michael Meadows, Susan Forde, Jaqui Ewart, and Kerrie Foxwell 2005); its role in facilitating dialogue between different parts of the community (William Siemering 2000; Susan Forde, Kerrie Foxwell, and Michael Meadows 2002; Kristy Martin and Michael Wilmore 2010); its role in encouraging and maintaining a sense of place (Sara Beth Keogh 2010); in reducing social isolation (Maryanne Read and Ralph Hanson 2006) and in working with marginalized groups for equality (William Barlow 1988; Gerald 
Sussman and J.R. Estes 2005; Sarah Baker 2007). In short, community radio breaks with traditional, mainstream models of media production in that community members are not an audience in the traditional sense. Rather, it retains at its core a "participatory" relationship with its multiple communities (Bruce Girard 1992, 13). However, as Traudel Günnel notes "Many stations have difficulties involving the target groups they aim to address, for example, women and so-called 'socially disadvantaged groups'... Strategies to involve these target groups seem to be missing" (Traudel Günnel 2008, 87). Günnel's work thus points to a potential democratic deficit within community radio itself, a tendency to underrepresent women as members of the community.

Transnational research notes that women's rates of participation are generally lower than for men in all areas of radio production except for finance and administration (Peter Lewis 1994). Where there were paid staff in community radio only $22 \%$ were female (Lewis 1994). Similarly, Brigitte Jallov's study on Mozambique found that "two out of thirty two radios on air had no women involved at all; one radio had only two women and most of the rest of the radios had around 15-25 per cent women" $(2007,343)$. Mitchell's work $(2002,2015)$ has done much to establish studies of women's community radio as an important dimension of feminist media studies and particularly so in the case of women's agency and participation in radio production. Mitchell argues that women's approach to radio programming needs to be understood in terms of a complex range of influences, their radio use, lack of role models, dearth of confidence in broadcasting in an institutional context that is clearly male-dominated $(1999,82)$. Mitchell has shown how women are still absent or pigeonholed in gendered presenter roles (2002). She has emphasized how community radio, in the form of feminist activist radio has been "instrumental in reconfiguring modern spaces of identity and agency" (Mitchell 2015, 17). In the Irish context, Margaretta D'Arcy describes one such feminist radio service, "a low-powered neighborhood women's non-licensed autonomous radio station" called Women's Scéal Radio (Mitchell 2002, 167). This service broadcast primarily for a week in 1987 and intermittently thereafter, and so remains atypical of women's experience of community radio in Ireland. Currently community radio in Ireland does not include any ongoing specifically feminist space, in the form of a dedicated women's station. Mitchell's findings therefore are less applicable in terms of women's participation in community radio in Ireland because of the gender mixed nature of Irish stations. The question of how women do fare in terms of gender equality in their participation in Irish community radio is thus the key focus of this paper.

A most useful theorization of the concept of participation in community radio and an invaluable framework for creating a new model of women's participation therein is offered by Rosemary Day $(2009,2011)$. Day's framework offers seven cumulative levels to describe the form and quality of participation enabled by community radio, relative to public service or commercial media (Day 2011, 197). As outlined on the right in the table below, Day argues that the first three levels of participation center on access and participation in terms of presenting or speaking on air. The next, fourth, level of participation is "mediated participation" whereby people engage in producing and presenting programmes. The fifth level, where community media departs from public service and commercial models of broadcasting is described as "participation" which Day outlines as involving "Schedule, programme planning, autonomous production after training by station, open to community" (Day 2009, 126). The sixth level of participation 
is "self-management" where the management of the station is open to the community and unmediated by outside groups (126). The final, seventh level of participation Day describes as "Full and active participation" in the form of "ownership by the community" (2009, 126). Day's seven levels of participation can be adapted to model women's participation in community radio, that adaptation is outlined on the left of the table below. This adapted model offers a new theorization of women's participation in community that describes their position at a structural level within the sector. A structural perspective on women's experience of gender inequality in participation in community media is important as a synthesis of disparate research on various dimensions of their experience which can be incorporated into a single summary of their overall experiences of gender inequality in community radio.

Day's seven types of participation are here condensed into a five-part framework, see Table 1, which offers a structural picture of women's participation in community radio. The first or most basic category of participation, which encompasses Day's first three types in one, is "Presenting," a type of participation whereby women can have their voices included on air, either by speaking on programs or by presenting them. The second level of women's participation, adopted from Day's framework, is "Producing" whereby in a similar vein to Day's "mediated participation" women can produce their own programmes. The third category of women's participation corresponds with what Day describes as "Participation," that is, women are involved in scheduling, planning, training and autonomous engagement with community broadcasting. The fourth category of participation adapted from what Day describes as "self-management" is renamed "Management," whereby women are involved in the management of stations and decision making in the running of the station, without influence from outside parties. The final level of engagement is full and active participation through what Day describes as ownership but which I adapt here to a more specific engagement with "Governance." The findings below describe women's participation in community radio in terms of the five dimensions of this framework and shows that while women's participation at the higher levels of community radio is positive at the lower levels they are challenged to engage in presenting, producing and participation by gender inequalities. This key finding infers that the framework needs to be seen not as linear or a "pipeline" of progression but rather underpins the fact that while in some dimensions of participation women are engaged, challenges remain in the core activities of community radio production.

Table 1. A framework for women's participation in community radio.

\begin{tabular}{lll}
\hline Level & Type of participation & \multicolumn{1}{c}{ Day's Original Category Description } \\
\hline 5 & Governance & Level 7 Ownership \\
4 & Management & Level 6 Management \& decision making \\
3 & Participation & Level 5 Participation \\
2 & Producing & Level 4 Mediated Participation \\
1 & Presenting & Level 1-3 Access and controlled participation \\
\hline
\end{tabular}




\section{Methodology}

Data were collected in 2017 through a mixture of methods. A short qualitative survey was sent to all 21 community radio station managers in order to get a sense of basic quantitative data on the number of women participating in community radio. The survey also asked some qualitative questions about the characteristics and scope of women's participation at the various stations. The rate of return from the survey was low with only five stations initially returning data. This low response of $4.2 \%$ may signal a fatigue with research within the sector or a significant disinterest in the question of women's participation in the sector. The latter interpretation of the situation is reinforced by the fact that a 2017 audit of the community radio sector commissioned by the sector's representative organization CRAOL failed to incorporate gender as a category of data collection. Supplementary information on gender data was sought and received from CRAOL. While the data from the short survey is very limited and no representative statistics can be drawn from it, the qualitative responses included with the survey do offer some insights into the attitudes to gender within stations. Subsequent to the survey, a focus group was conducted with 10 women who self-selected to participate in a CRAOL women's networking event. They participated because they were interested in the question of gender equality. They comprised a mixture of station managers, presenters, staff and volunteers. Qualitative data were gathered as part of that meeting based on discussions of themes presented by the author, which were derived from a review of literature on women and community radio production. Those themes included: the rates of women's participation; gender and programme content; women presenting programmes; barriers to participation; and the benefits of community radio to women. The larger group worked in small subgroups to discuss the theme and the main points of their discussion on each theme was recorded in note form and presented back to the main group. Apart from the focus group, semi-structured interviews were conducted with five additional participants, from various other community radio stations. These participants were selected through a random snowball sample and because they represented broad categories, including station managers, paid workers, community employment scheme workers, interns and volunteers, which overlapped with those who participated in on-air and off-air roles within program making, fundraising and administration. All information that could identify any of the 20 individuals described in the study was removed or changed, apart from loose role descriptions. Data were coded according to the theoretical framework developed above and findings were arranged under each of the categories devised within the framework. In the findings outlined below each level of participation is examined in turn to assess the nature and extent of women's engagement at that level. In conclusion, an overarching structural perspective on women's gendered position within community radio can be described based on the application of the framework.

\section{Level 1-presenting}

Gill (1993) noted, more than 20 years ago, that men's voices were more likely to be heard presenting on air, both on mainstream radio and in community stations. Currently, that status quo of male domination of the airwaves continues. With regard to 
mainstream radio in Ireland, a report published by the National Women's Council in 2015 "Hearing Women's Voices" found that current affairs programmes had poor representation of women presenters. When measured by time on air, on the national public service station, RTÉ Radio One, only $26 \%$ of all reporters' time was provided by female reporters, the equivalent figure for the national commercial station Newstalk, was 15\% female (BAI 2017a, 66). Only on RTÉ Radio One were there were more lead female than male presenter's voices on air during the week of programme monitoring, but the commercial stations had no weekday shows presented by women (BAI 2017a, 66). Subsequent to the 2015 study, the Broadcasting Authority of Ireland, which is the regulator for community radio, saw it as beyond their remit to require radio stations to put a quota of women presenters on air. The Chief Executive of the BAI commented in media reports "setting quotas for who your presenter should be, or just the principle of telling stations that you must have a certain number of presenters, it's not something we have done up till now" (Aoife Barry 2017). The introduction of quotas was named by the Minister for Communications as a possibility to redress imbalance in mainstream radio in Ireland. However, community radio was not mentioned nor examined in any of the gender research supported by the regulator, nor mentioned specifically in any of the public debates on gender and women presenters.

Although it has been neglected in national discourses on gender equality the situation in community radio mirrors that of mainstream radio with women significantly absent from community airwaves. As one station manager put it "There aren't that many female presenters on radio..." (Survey respondent J). One woman presenter described her growing awareness of the absence of women on air "I began to become aware of the fact that women's voices and stories weren't there. Where are they...you just don't hear them on radio?" (Interviewee, O). Another respondent shared her understanding of why there was an absence of women's voices on community radio, which was framed in terms of women's confidence to participate. "If you talk to radio producers about why women aren't on air they'll say women don't have the confidence to, especially with current affairs. They'll ring women at short notice to come on air and a woman will have to make sure she's completely au fait with the whole thing. There's a confidence thing" (Focus group, B). Another station manager commented "Women often lack the confidence to broadcast... which stops women putting themselves forward for better time slots and individual shows" (Survey respondent $\mathrm{L}$ ). This lack of confidence was understood to extended also to women who were older, as one station manager observed "We have a lot of retired men but not retired women... There's a lack of confidence in older and retired women" (Survey respondent K). While there was an awareness of women's absence from presenting roles, due to this confidence issue, station managers did not have a very strong sense of how to address the imbalance and the confidence issue.

One manager connected women's willingness to present with their experiences and confidence around technology more specifically, which contrasted with men's apparent ease in technical settings. "There's a difference in attitude towards the technology... Younger women are even a bit afraid of the technical side and they'll say things like they want to be a researcher, work behind the scenes, whereas the guys, younger, older it doesn't matter, they figure they can do it. They're saying straightaway 'When am I getting my programme?'" (Interviewee P). This insight into gendered differences in approaches to technology, or immediate confidence in attitude towards supposedly 
technical tasks had led one station manager to attempt to address the situation with some training for women on technology. She did this because she saw it as a necessary skill for community presenters where resources often do not exist to facilitate technical support for people who exclusively wanted to present. As the manager put it "From my experience so far, women (presenters) have the idea that someone else will do tech support... I've tried to change that with training, and I've given quite substantial training but there's a fear behind it but it's not actually that hard which is the interesting part of it" (Survey respondent J). Unfortunately, there was no sense, again due to a dearth of research and gender monitoring within community radio, of how prevalent, how widespread or how effective such small-scale and localized interventions have been in addressing women's absence from presenting roles.

The absence of any centralized or coordinated approach to addressing women's participation on air emphasized the isolation of each station in dealing with this issue of women on air. There was a limited understanding of why women weren't on air, framed in terms of women's lack of confidence, rather than men's overconfidence or dominance. Moreover, each station attempted to solve the problem in a singular rather than collective manner. There was no sense of women's voices on air being an urgent or priority issue for stations, for the sector nor for the national regulatory body, despite the sector's remit to be inclusive of all. While women's absence is often "blamed" on their lack of confidence the broader sociological conditioning and patterns of participation that might lead women to believe radio was male dominated were not named explicitly by any of the respondents as reasons for women's absence. Rather than framing women's absence from the airwaves in terms of theories of flexible sexism (Gill 1993) which place the responsibility for women's absence on the gendered structural constraints within stations, such as precedent, normative practice, masculine culture, gender-stereotypical role allocations (Anne O'Brien 2015), community radio practitioners place the responsibility with women themselves, who individually lack "confidence." Community radio was not a space in which those social forces were challenged and tied to an explicit prerogative of recruiting more women's voices. Thus in terms of the framework's first level of participation, presenting is clearly gendered for Irish women who are underrepresented in presenting roles with their voices less prevalent than men. This is problematic for women because if they can't have an equal experience of the most fundamental aspect of community radio they are more likely to be excluded from other dimensions of participation. This gender inequality is equally problematic for community radio which fails to monitor women's airtime, has no policy aimed at explicitly gender-based inclusivity at this level and ultimately fails to achieve its stated aim of participation for all at the most fundamental level of presenting.

\section{Level 2-producing}

Respondents understood that community radio offered them a valuable opportunity to participate in the process of radio production "Community radio is great and a great place to get experience and to start off" (Interviewee, S). Within the context of producing there was an optimistic sense amongst respondents that women approached content production in ways that were not normative, which were explicitly linked to gender and which were well facilitated by the ethos and approach of community radio. 
As one presenter put it "I think community radio can come at stories differently... that does come from having more female voices, more presenters and more women involved...." (Interviewee, O). One of the ways in which radio production was gendered was that women put more emphasis on people in stories. As another presenter observed, relative to the male producers at her station, "I would have gone for more human-interest stories" (Interviewee R). Another station manager agreed that women produce differently. With reference to her own productions she noted that

I would have been very conscious of getting women into studio and on air it would have always been on my mind. I think mainly that's because of the types of subjects and issues that would have been of interest to me and other women at the time, the station wouldn't have gone to those topics before I was there. (Survey respondent $\mathrm{N}$ )

Another respondent pointed out how gender can influence the coverage of a topic by a producer. She described how she took a non-normative approach to a domestic violence story about the murder of a woman within the local community.

Someone had just been killed... I didn't make a report and play it on my programme directly after the incident. I waited a few days and spoke to the members of the community and brought them into the station to have a discussion about it. I definitely think the coverage was different. The piece wasn't so much about the case as the community... I don't think that a male (producer) would have taken that approach to it. (Interviewee R)

While these programmes were not normative and did place women's gendered experiences at the center of radio production, they were not necessarily explicitly feminist nor "about" gender in their content. This pattern is reflected also in international research, which has noted that "many programmes produced by women's stations put an emphasis on everyday women's lives rather than on overtly political feminist content" (Mitchell 2000, 350). Similarly, Marian Bredin (1991) noted that in Canadian community radio, despite the participation of women in production roles, stations lacked feminist content and intersectionality amongst the women producers involved. Despite the absence of an explicitly feminist agenda in radio content, one respondent was clear that women's presence in producing content for programmes was nonetheless very important, because it created a "map" of how women can envision themselves participating on radio at the level of producing, and specifically in producing more women's stories. She noted "I think women need to hear other women's stories, it's a practical thing. They can map how women do radio and think 'Well if she can do it, so can I'. And that's why I think the thing of women telling their own stories is really important for other women and it's different to men" (Interviewee I).

Despite these positive experiences for women engaged in production, other respondents noted that there was still gender inequality between participants in terms of production work. As Mitchell has noted in previous research, just as women's voices are absent on air in community radio, stations largely tend not to produce very much programming specifically for women, rather they produced "islands of women's activity - rarely more than an hour a week where there were some women presenters and specialist women's programmes" $(1999,79)$. This finding is replicated in the contemporary Irish context where there is similar evidence of an "islands" approach to producing women's programmes. One station manager summarised women's entire engagement with production in term of a couple of islands "We have a weekly women's programme and 
special programme on International Women's Day" (Survey respondent M). One respondent described how important it was to have that dedicated "women's" hour of radio, for her own participation in community radio, in order to develop her own practice in production and to get more women's voices on air. She describes how her "island" of programming came about, she was encouraged to propose a women's hour by her station manager who "was equally passionate about women being involved" (Interviewee I). The programme involved "interviewing a woman or women for an hour with some music" and the participant was fully supported in doing this by the station manager (Interviewee I). The only negative response came from a fellow presenter "a guy who'd been presenting there for years and he said 'oh that's ridiculous, talking to one woman for an hour, that's crazy you'll never get them'" (Interviewee I). Undeterred the programme ran successfully for over two years and as the respondent noted "It proved to me that there is a huge untapped well of stories and of women's experiences that women want to hear" (Interviewee I).

Despite women's positive experience as producers, even if only of limited "islands" of content, nonetheless some producers were clear that community radio was not facilitating optimum participation for women in terms of the framework's second level, producing. As one respondent notes "One of the most frustrating things about radio in Ireland is the fact that I don't hear myself reflected and that worries me" (Focus group, $\mathrm{H})$. Respondents explained that what in part prevented more women producing programmes was an idea upheld by the community stations that some sort of normative metric of "merit" or "quality" should be applied to content commissioning and it should take precedence over gender balance in participation. As one station manager put it "In proposing programmes it's the programme's strength and quality is what is important first" (Survey respondent K). However, if community radio is primarily about participation at the level of producing radio programmes, and if producing is to be done by all members of the community then participation needs to be more explicitly prioritised above the "quality" of output. The idea of "quality" and what is of interest in terms of content has been shown to be very gendered (O'Brien 2015) so applying this metric to women's productions is another barrier to fair and equal participation in gender terms. The ideal of participation in producing should be more forcefully applied in the sector in terms of explicit policy, in practice and by changing structures to facilitate women's greater engagement and the presence in shaping the content of community radio productions. Some respondents were confident that community radio could offer a way forward to change gender inequality for radio producers. As a producer noted

What I found with my programme was that if you give a woman the space and the time to tell her story, in her own way, without too much pressure, and radio allows for that because it's such an intimate medium, then I think it can work very well for telling women's stories and that's important... And this is where community radio matters because it's accessible. It gives women a platform, if they have the courage to take it. (Interviewee Q)

However, it is still the case that women's individual "courage" is what is understood to be required in order to have women participate at the second level of producing, rather than an expectation that the structures of community radio are at fault for not including women on more equal terms as producers of programmes. 


\section{Level 3-participation}

With the proviso of a very low rate of return on the quantitative survey described above, the estimate offered by station managers on the rates of female to male participation in community radio appear to show a 40:60 ratio of women to men, with women dominating 2:1 in administrative roles and being under-represented in a 1:2 ratio in technical roles. Qualitative comments from the survey confirmed that women were under-represented as participants in the sector. As one station manager noted "I don't think that we have balance among volunteers at the station or in the sector... I'd say it's about 70:30 across community radio" (Survey respondent J). Another respondent agreed that "More men than women volunteer" (Focus group H). Another said "It's a hierarchy of men" (Focus group B). Data from the focus group corroborated what emerged in the qualitative section of the survey with women noting that "community radio had predominantly male voices" (Focus group D). Respondents named some of the barriers they saw to women's participation in community radio. One respondent noted that "seeing a place full of men, feeling that it's not for women... subconsciously that was intimidating" (Focus group E). The dearth of leisure time available to women to volunteer was understood as a barrier. As a station manager noted "I think the biggest barrier to women getting involved in Community Radio is that they don't have the time" (Focus group E). Another perceived cause of women's absence was women's disproportionate childcare burden. As one station manager put it "I think childcare is a big issue for a lot of women" (Survey respondent J). However, a number of respondents also saw the issue lying with women "I think women very often lack the confidence to broadcast" (Focus group T). These explanations corroborate Jovia Musubika's study in Uganda, which noted obstacles to participation included a disproportionate and immense work and care-work burden faced by women $(2008,343)$.

Interestingly, these causes of gender inequality in participation were all framed as lying outside of the sector's remit, control or influence, only one respondent noted that "more supports are needed for women to participate" (Focus group F). More typically, a station manager noted "Community groups in the area are not gender balanced so it's difficult to represent balance on air at times" (Survey respondent K). Several respondents similarly framed their position as "gender neutral" rather than obliged to proactively seek out women. As they variously put it "We welcome male and female participation... It's up to both genders to get involved with the station... We don't put obstacles in anyone's way..." (Focus group $F, C, G$ ). Only one station documented a proactive stance on attempting to address the gender imbalance in participation "...through more involvement with local women's groups" (Survey respondent N). Respondents typically framed solutions to the problem of women's participation in terms of offering more equality of opportunity rather than adopting a more social-justice oriented position of aiming for equality of outcome. As a manager put it "Gender balance is difficult because of the voluntary nature of the station. We aim for equality of opportunity" (Survey respondent L). A number of respondents did not see that their community had any duty to intervene to proactively engage with more women. Studies that have pointed to the difficulties women experience with asserting their right to participate (Mitchell 1999) are thus still very relevant in terms of the third level of the framework, where women's participation is still documented nor treated as a concern or "problem" for society more broadly rather than for their community station. 


\section{Level 4-management}

With regard to the fourth level on the gender participation framework, respondents noted that women had a strong presence in station management. However, in numerical terms there were 7 out of 21 station managers, or one-third, who were female. Despite not being half of the population of managers, women were generally deemed to be positive role models for women in the sector. As one volunteer noted about her station manager "I found her to be a very strong role model. She worked a lot with AMARC and she really created a place for herself in community radio ... just the fact that she was there as the manager, in one of the biggest stations, gave me confidence" (Interviewee, S). In addition to offering opportunities to manage and role models for women aspiring to those roles, women's style of management in community radio was described by respondents in terms that can be understood to be relational (Mary Uhl-Bien 2011). Relational management describes leadership as a socially constructed change process, that operates through the process of relating, and which is inherently subjective and interdependent (67). Leadership in that sense is not restricted to hierarchical positions or management roles but rather it is seen as a set of influential acts of organizing that come to structure interactions and relationships within organizations. Respondents documented how women's management in the station worked on the basis of relational "bonds." As a respondent put I "It's hard to tell if management styles are different for women and men... I think women in general are just more talkative and form bonds easier..." (Focus group E). Another respondent described the relations of trust that female managers placed in them "I couldn't believe that somebody was giving me this radio platform to practice with... What I liked about her as a manger was that she left me to it. I was given freedom and not put under pressure..." (Focus group G). Moreover the communicative style of the women managers was something that helped volunteers to learn and improve, as one noted "The station manager in my case was very supportive and gave feedback after every show. The encouragement and the fact that she appreciated the input and her feedback was great" (Focus group D).

Women's presence in management created a homophillic network for women that could counter the more widespread sense of the media operating as an "old boys club." Respondents noted that women managers sought out other women to go on air "Any female volunteers that come in, I do absolutely direct them towards getting on air" (Survey respondent K). Another manager concurred "I did go after female volunteers... I would be very much looking to get women involved in the project" (Survey respondent N). Respondents noted that women often acted as sponsors of other women's work \& progress. As one station manager noted, with regard to achieving her post, having a female sponsor made all the difference to her progress

I saw that the job of station manager had come up and I had no intention of going for it. Then my manager said to me 'are you going for that?' and I said 'no' and I remember she directly said 'what's wrong with women! There's two men here going for that job and they've way less experience than you and you're sitting there thinking you wouldn't get it? And she encouraged me to go for it-she actually told me to... so I did. (Survey respondent M)

The fact that women are better represented in management, despite being more underrepresented at lower levels of participation raises questions for further research in order 
to understand why this dynamic is at play. If viewed in terms of research on gender and work a possible explanation for women's dominance in community station management is that it constitutes a "pink ghetto" a role that does not offer any further progress for women's careers in media industries.

\section{Level 5-governance}

The final level of participation described in the framework, governance, includes the institutional and organisational structures of community radio, which ideally should express its objective of having women participate equally with men. As Mitchell notes women should find community radio "more accessible because of its open structures" $(2000,199)$. On a positive note, some aspects of the structures of Irish community broadcasting did facilitate women's participation in the sector. This occurred mainly because of the regulator's capacity to shape and direct the broadcast sector in terms of policy requirements. Currently, as part of the licensing contract for community radio stations the BAI requires that "The Executive Organ of the Contractor as specified in the certificate of the Secretary shall not consist, as to $60 \%$ or more of its membership, of either men or women" (BAI 2017b, 15). As Nessa McGann notes these quotas are "structurally critical to the continued participation of women at crucial levels of operation" (in Day 2007, 92). There was a clear understanding amongst community media participants that gender balance was a useful requirement at board level. However they also noted that this requirement was difficult to meet "It's definitely an issue trying to get women for the board" (Focus group C).

In light of the challenge of finding women to participate on boards, respondents expressed a sense that the regulator could be more proactive in encouraging women's participation in community radio governance, by making gender balance a requirement for the commercial radio sector, which would give women a pathway into boards in commercial and paid contexts. As a station manager noted "I'm not sure what the regulator does at all to encourage gender balance... it seems wrong that it's only for the community sector, it should be enforced for all the stations, commercial as well. It doesn't make sense and it's a barrier to women if they're not getting involved in boards in the commercial sector" (Survey respondent K). One participant was clear that a greater range of governance instruments could be applied to encourage gender diversity. On respondent proposed attaching gender quotas to public funding mechanisms which could effectively address the gender inequality in community media. "The BAI falls down on gender balance... To get more gender balance, I think it would take quotas... the BAI need to get serious and link funding to representation, not just presenters but including presenters. The quota model backed up with training would work really well" (Focus group A). In its most recent strategy statement in 2017 the BAl did not adopt a quota approach to gender participation in either commercial or community radio. Thus although women are encouraged to participate in community radio at the fifth, governance level, some strategic blocks on women's participation remain, mainly that is no imperative currently within the regulatory or funding frameworks of community broadcasting in Ireland to strongly advocate for greater gender equality. 


\section{Conclusion}

A number of challenges exist to women's equal engagement in the sector at each of the levels described in the framework. At level 1 presenting, women's absence from the airwaves is generally understood to occur because they lack the confidence to participate. However very little if any research has been done to unpack this idea of "confidence" and how it is created or destroyed in women and girls, specifically in the context of presenting radio programmes. While stations do on occasion seek to "fix the problem" of women's confidence through training initiatives there a dearth of more radical or feminist objectives to address what is truly at stake for women in presenting radio, which may more radically challenge normative presenting practices. Similarly, at level two productions, women's content continues to exist mainly in "islands" of programming. Women's approach to production, which was seen as different, must be therefore more explicitly valued in order that women see community radio as "theirs." At level three, participation, many of the causes of gender inequality at this level were accepted as lying outside of community radio's jurisdiction, with very little emphasis on the sector questioning, researching or offering appropriate supports to women in order to more fully participate. At level four, management, while respondents were enthused that women had a strong presence at this level in reality they are only one-third of all managers. At level five, governance, community radio in Ireland has been supportive by requiring gender balanced boards at a licensing level, but in practice the sector has tended to adopt a rather neutral position on gender balance as a strategic governance outcome, and needs to be more proactive about fulfilling its remit to be the voice of all of the people. A more proactive stance on the part of the national umbrella body, Craol, and on the part of the regulator would do much to set a clear and meaningful objective for greater gender equality in a medium that is primarily about equality and participation for all members of society.

The innovative framework outlined here offers a way to examine women's exclusion, not in a piecemeal way, but in an overarching approach, where a bird's eye view of women's gendered position within community radio can be constructed. The framework can potentially be used to examine cases of gender inequality in other places and contexts. The framework also opens up the possibility for comparison across sites. The framework can be more theoretically honed and refined and further research is needed to understand how each of the dimensions of the framework interact to reinforce women's exclusion from community radio. Understanding women's exclusion from community radio is important because its failure to incorporate women at all levels of participation means that is failing to truly achieve its potential as an alternative mode of communication to mainstream media. Community radio's remit explicitly calls for the inclusion of the voiceless, and therefore should explicitly target participation from women, who are underrepresented in mainstream radio. This participation should be in evidence at all levels of community radio, in its structures of ownership, in its control and financing, women's participation should be a dimension of community radio's visions and aims, which are to provide news and information relevant to the needs of community members, to engaging them in public discussion and to contribute to their social and political empowerment (Nicholas W Jankowski and Ole Prehn 2003). If community radio is "ideally audience-controlled, autonomous and concerned with challenging power" (Patricia Elliott 2010, 9) how can it ever achieve these goals if women 
remain systematically excluded from community radio? As Mitchell puts it "Feminist production should be about the politicisation of culture in resistance to patriarchal oppression" $(1999,75)$ the population of this framework with evidence from Ireland shows that there is indeed much scope for a feminist intervention towards greater gender equality in community radio at all levels of participation.

\section{Disclosure statement}

No potential conflict of interest was reported by the author.

\section{Notes on contributor}

Anne O'Brien is a lecturer with the Department of Media Studies at Maynooth University. She has published a number of articles on the representation of women in radio and television, on women workers in creative industries, on women's leadership in media industries and examined why women leave careers in screen production. She has published a monograph on state development and cultural industries. She is a member of Screen Producers Ireland and a former appointee to the Broadcasting Authority of Ireland. E-mail: anne.obrien@nuim.ie

\section{References}

AMARC World Association of Community Radio Broadcasters. 2011. "Strategic Plan 2011-2014". http://europe.amarc.org/index.php?p=Strategic_Plan-2011-2014\&l=EN

BAI (Broadcasting Authority of Ireland). 2017a. "Strategy Statement" http://www.bai.ie/en/aboutus/our-strategic-goals/

BAI (Broadcasting Authority of Ireland). 2017b. "Community Sound Broadcasting Contract". http:// www.bai.ie/en/broadcasting/licensing-2/radio/

Baker, Sarah. 2007. "Young People and Community Radio in the Northern Region of Adelaide, South Australia." Popular Music and Society 30 (5): 575-590. doi:10.1080/03007760600835389.

Barlow, William. 1988. "Community Radio in the U.S.: The Struggle for a Democratic Medium." Media, Culture and Society 10: 81-105. doi:10.1177/016344388010001006.

Barry, Aoife. 2017. "You Won't Hear a Woman's Voice, and It's Not Acceptable: What are Irish Radio Stations Doing about Gender Balance?". The journal.ie http://www.thejournal.ie/radio-stationsgender-balance-3564542-Aug2017/

Bosh, Tanja. 2016. "Gender in South African Newsrooms." Journal of African Media Studies 8 (3): 295-304. doi:10.1386/jams.8.3.295_1.

Bredin, Marian. .1991. "Feminist Cultural Politics: Women in Community Radio in Canada." Resources for Feminist Research 20 (1-2): 36-41.

Carter, Susan. 2004. "A Mic of Her Own: Stations, Collectives and Women's Access to Radio." Journal of Radio Studies 1 (2): 169-183. doi:10.1207/s15506843jrs1102_3.

Day, Rosemary. 2009. Community Radio in Ireland: Participation and Multiflows of Communication. Cresskill, NJ: Hampton Press.

Day, Rosemary. 2011. "New Technologies and the Facilitation of Participation in Community Radio Stations." In Radio Content in the Digital Age: The Evolution of a Sound Medium, edited by Angeliki Gazi. United Kingdom: Intellect Books.

EIGE (European Institute for Gender Equality). 2013. Advancing Gender Equality in Decision-Making in Media Organizations Report. Luxembourg: Publications Office of the European Union.

Elliott, Patricia. 2010. "Another Radio Is Possible: Thai Community Radio from the Grass Roots to the Global." The Radio Journal - International Studies in Broadcast and Audio Media 8 (1): 7-22. doi:10.1386/rjao.8.1.7_1. 
Forde, Susan, Kerrie Foxwell, and Michael Meadows. 2002. "Creating a Community Public Sphere: Community Radio as Cultural Resource." Media International Australia 103 (1): 56-67. doi:10.1177/1329878X0210300109.

Gill, Rosalind. 1993. "Justifying Injustice: Broadcasters Accounts of Inequality in a Radio Station." In Discourse Analytic Research: Readings and Repertoires of Texts in Action, edited by Erica Burman and lan Parker, 75-93. London: Routledge.

Girard, Bruce. 1992. A Passion for Radio: Radio Waves and Community. Montreal: Black Rose Books.

Grubbs, Jim. 2004. "Women Broadcasters of World War II." Journal of Radio Studies 11 (1): 40-54. doi:10.1207/s15506843jrs1101_5.

Günnel, Traudel. 2008. "The 'Dual Role' Approach: Encouraging Access to Community Radio." The Radio Journal - International Studies in Broadcast and Audio Media 6 (2-3): 87-94. doi:10.1386/ rajo.6.2-3.87/4.

Jallov, Brigitte. 2007. "Creation of a Women's Community Radio Movement" in Jane Arthurs \& Usha Zacharias "Introduction Women and Radio." Feminist Media Studies 7 (3): 333-348.

Jankowski, Nicholas W., and Ole Prehn. 2003. Community Media in the Information Age: Perspectives and Prospects. New Jersey: Hampton Press.

JNLR (Joint National Listenership Research). 2017. JNLR Press Release Report 32017 Dublin: Ipsos MRBI http://www.bai.ie/en/media/sites/2/2017/10/October-2017.pdf

Karpf, Anne. 1987. "Radio Times." In Out of Focus, edited by Kay Davis, 175-180. London: Women's Press.

Keogh, Sara Beth. 2010. "The Importance of Place in Community Radio Broadcasting: A Case Study of WDVX, Knoxville, Tennessee." Journal of Cultural Geography 27 (1): 77-98. doi:10.1080/ 08873631003593265.

Lewis, Peter. 1994. Community Radio - Employment Trends and Training Needs. Report of Transnational Survey. Sheffield: AMARC Europe.

Liddy, Susan. 2015. "Missing in Action: Where are the Irish Women Screenwriters?" Film Ireland http://filmireland.net/2015/04/20/missing-in-action-where-are-the-irish-women-screenwriters/

Luscombe, Anya. 2013. Forty Years of BBC Radio News. From the Swinging Sixties to the Turbulent Noughties. Frankfurt am Main: Peter Lang.

Martin, Kristy, and Michael Wilmore. 2010. "Local Voices on Community Radio: A Study of 'Our Lumbini' in Nepal." Development in Practice 20 (7): 866-878. doi:10.1080/ 09614524.2010.508104.

Meadows, Michael, Susan Forde, Jaqui Ewart, and Kerrie Foxwell. 2005. "Creating an Australian Community Public Sphere: The Role of Community Radio." The Radio Journal 3 (3): 171-187.

Mitchell, Caroline. 1999. "Women's (Community) Radio as a Feminist Public Sphere." Javnost- The Public 5 (2): 73-85. doi:10.1080/13183222.1998.11008676.

Mitchell, Caroline. 2000. Women and Radio: Airing Differences. London: Routledge.

Mitchell, Caroline. 2002. "On Air/Off Air: Defining Woman's Space in European Women's Community Radio." In Community Media in the Information Age: Perspectives and Prospects, edited by Nicholas W. Jankowski and Ole Prehn. Cresskill, New Jersey: Hampton Press.

Mitchell, Caroline. 2015. "Re-Sounding Feminist Radio: A Journey through Women's Community Radio Archives." Feminist Media Histories Journal 1 (4): 126-143. doi:10.1525/fmh.2015.1.4.126.

Musubika, Jovia. 2008. "Women's Potential and Challenges in Community Radio: The Case of Mama FM." Agenda 22 (77): 127-134.

O'Brien, Anne. 2015. "Producing Television and Reproducing Gender." Television and New Media 16 (3): 259-274. doi:10.1177/1527476414557952.

Read, Maryanne, and Ralph Hanson. 2006. "Back to the Future: Allegheny Mountain Radio and Localism in West Virginia Community Radio." Journal of Radio Studies 13 (2): 214-231. doi:10.1080/10955040701313297.

Servaes, Jan. 1999. Communication for Development: One World, Multiple Cultures. Cresskill, NJ: Hampton Press. 
Siemering, William. 2000. "Radio, Democracy and Development: Evolving Models of Community Radio." Journal of Radio Studies 7 (2): 373-378. doi:10.1207/s15506843jrs0702_10.

Steward, Sue, and Sherly Garratt. 1984. Signed, Sealed and Delivered. True Life Stories of Women in Pop. London: Pluto Press.

Sussman, Gerald, and J.R. Estes. 2005. "KBOO Community Radio: Organizing Portland's Disorderly Possibilities." Journal of Radio Studies 12 (2): 223-239. doi:10.1207/s15506843jrs1202_4.

Uhl-Bien, Mary. 2011. "Relational Leadership and Gender: From Hierarchy to Relationality and Relational Leadership Theory: Exploring the Social Processes of Leadership and Organizing." In Leadership Gender and Organization, edited by Patricia Werhane and Mollie Painter-Morland, 65-108. Dordrecht: Springer. 